\title{
Comparative Osteometric Study of Long Bones in Yankasa Sheep and Red Sokoto Goat
}

\author{
*'SALAMI, S. O., 'IBE, C. S., 'UMOSEN, A. D., ' $A$ AJAYI, I. E. and 'MAIDAWA, S. M.
}

'Department of Anatomy, Faculty of Veterinary Medicine, Ahmadu Bello University, Zaria, Nigeria ${ }^{2}$ Department of Anatomy, Faculty of Veterinary Medicine, University of Abuja, Abuja, Nigeria *Corresponding author: salamiwoye@yahoo.com

\begin{abstract}
Summary
A morphometric study was undertaken on the long bones in two predominant breeds of small ruminant in Northern Guinea Savanna zone of Nigeria, to determine their anatomical differences, and thus, provide a means of differentiating the remains of these two species during zooarchaeological studies and gross anatomy practical session. The pelvic and pectoral limbs from 15 Yankasa sheep and 15 Red Sokoto goats of both sexes were used for this study. The long bones of the pectoral limbs considered were the humerus, radius, ulna and metacarpal III while those of the pelvic limbs were the femur, tibia and metatarsal III. Parameters considered were the mean weights, lengths and diameters of the proximal extremity, mid-shaft and distal extremities of these bones. There was a significant difference $(p<0.001)$ in the length of the long bones between the two species, with that of the Yankasa sheep being significantly longer than the Red Sokoto goat. Also, the differences in weights and diameters of the proximal, middle and distal shafts of the tibia between the two species were statistically different $(p<0.001)$. Conversely, the differences in the proximal and distal diameters of the femur between the two species were not statistically significant $(p>0.05)$. Factors that may be responsible for these differences were discussed. It was concluded that the bones of the Yankasa sheep and Red Sokoto goat can be differentiated by the disparity in the length of the long bones or the disparity in the entire morphometry of the tibia bones.
\end{abstract}

KEYWORDS: Yankasa sheep; Red Sokoto goat; Long bones, Osteometry.

\section{INTRODUCTION}

Sheep and goats belong to the tribe Caprini of the family Bovidae in the sub-order Ruminantia of the order Artiodactyla (Zeuner, 1963; Epstein, 1971; Corbet, 1978; Corbet and Hill,
Hill, 1980; Ryder, 1984). The tribe Caprini is comprised of five genera. Two of these genera, Capra and Heniitragus, are true goats; one genus, Ovis, is the sheep; the other two genera, Ammotragus and Pseudois are goat-like sheep or sheep-like goats (Wilson, 1991).

Although there are considerable number of morphological differences between the two species, the most simple and effective visual way of distinguishing sheep from goats is the carriage of the tail. In all domestic forms, goats' tails are erect while those of sheep are pendent (Ryder, 1984). The male goats also have beard and caudal (tail) scent glands while in the sheep, the male have a mane with long hair and horn. The female goats have horns and long neck while in sheep the female lack horn and are usually longer than the male in body form (Wilson, 1991). Other extant data on the use of body measurements in differentiating small ruminants include lengths of hip and fore limb as well as height of the rump and wither (Afolayan et al., 2006; Salako, 2006a; 2006b).

Differentiating the remains of the two ruminants in a zooarchaeological survey or during gross anatomy practical session in Veterinary Colleges is difficult. This is due to the fact that all the aforementioned criteria for such differentiation are for live or not yet flayed slaughtered animals. The skeletal system stands out as one of the body structures that has been used and still being used for the characterization of different species of animals including humans (Watson, 1972; Guintard and Lallemand, 2003). This is because most of the parameters considered such as shape, height, length and size are easily accessible in the skeleton. This study was therefore, conducted to compare morphometrically, the long bones of the Yankasa sheep and Red Sokoto goats for easy differentiation of 
their remains and for comparative studies.

\section{Materials and Methods Specimen collection}

15 sheep and 15 goats of both sexes and estimated age of one year, bought from middle men at the Zaria Abattoir were used. The sheep were of Yankasa breed while the goats were of Red Sokoto breed. These are the predominant breeds of sheep and goat in north central zone of Nigeria where the study was conducted. Physical examination of all animals revealed no sign of limb deformity. The animals were slaughtered using standard humane procedures and the limbs harvested.

\section{Preparation of specimen for maceration}

The soft tissues attached to the long bones such as muscles, fascia, tendons and ligaments were removed using scapel and scissors. The specimens were then arranged into two macerating buckets, one for sheep and the other for goat. Tap water was added to submerge the specimen. This was allowed to stay for 3 days after which the water was changed. To the changed water, 1-1.5 M Potassium hydroxide $(\mathrm{KOH})$ was added to facilitate total removal of the remaining soft tissues from the bones. The macerated bones were dried for 2-3 days after which they were boiled with detergent to remove bone marrow and fat. The bones were allowed to dry for the second time, bleached with hydrogen peroxide $\left(\mathrm{H}_{2} \mathrm{O}_{2}\right)$ and washed with detergent and brush. They were dried for 2-3 days. Thereafter, detached articular cartilages during the maceration process were fixed back using glue.

\section{Measurement of the bones}

Weights of the bones were obtained using a sensitive electronic balance (Mettler balance P 1210, Mettler instrument AG. Switzerland; sensitivity: 0.001g). Lengths of all the bones were traced with a thread and the length of the thread was obtained by stretching the measured length of the thread against a centimeter rule. Diameter of the bone extremities and the midshaft were measured in millimeters using vernier calliper (MG6001DC, General Tools and Instruments Company, New York; sensitivity: $0.01 \mathrm{~mm}$ ). The result obtained was converted to centimeters. All recorded weights, lengths and diameters were expressed as mean \pm SEM
(Standard Error of Mean) and subjected to statistical analysis using Statistical Package for Social Sciences (SPSS) version 17.0. Paired sample t-test at 95\% confidence interval was used to determine the level of significance between the two species. Values of $\mathrm{p}<0.05$ were considered significant.

\section{RESULTS}

The mean weights of the humerus, radius, ulna, metacarpal III, femur, tibia and metatarsal III in the Yankasa sheep were $34.627 \mathrm{~g}( \pm 0.695)$, $26.700 \mathrm{~g}( \pm 0.283), 22.467 \mathrm{~g}( \pm 0.198), 18.740$ $\mathrm{g}( \pm 0.243), 38.740 \mathrm{~g}( \pm 0.225), 36.360 \mathrm{~g}( \pm$ $0.327)$ and $17.567 \mathrm{~g}( \pm 0.366)$, respectively. Similarly, the mean weights of the humerus, radius, ulna, metacarpal III, femur, tibia and metatarsal III in the Red Sokoto goat were $30.240 \mathrm{~g}( \pm 0.728) 25.647 \mathrm{~g}$ ( \pm 0.327$), 22.153$ $\mathrm{g}( \pm 0.241), 17.920 \mathrm{~g}( \pm 0.209), 36.733 \mathrm{~g}( \pm$ $0.317), 32.927 \mathrm{~g}( \pm 0.217)$ and $15.133 \mathrm{~g}( \pm$ 0.234 ), respectively. These values were represented in the bar chart indicated in figure 1. There was no significant difference $(p>0.05)$ in the ulna weight between Yankasa sheep and Red Sokoto goats. However, the differences in weights of other long bones between the two species were statistically significant at varying probabilities, with the Yankasa sheep being heavier than the Red Sokoto goat.

The mean lengths of the humerus, radius, ulna, metacarpal III, femur, tibia and metatarsal III in the Yankasa sheep were $14.433 \mathrm{~cm}( \pm 0.179)$, $23.173 \mathrm{~cm}$ ( \pm 0.251$), 23.527 \mathrm{~cm}( \pm 0.256)$, $16.427 \mathrm{~cm}$ ( \pm 0.209$), 16.280 \mathrm{~cm}$ ( \pm 0.188$)$, $17.793 \mathrm{~cm} \mathrm{(} \pm 0.258)$ and $15.280 \mathrm{~cm}( \pm 0.148)$, respectively. Similarly, the mean lengths of the humerus, radius, ulna, metacarpal III, femur, tibia and metatarsal III in the Red Sokoto goat were $12.960 \mathrm{~cm}$ ( \pm 0.114), $19.327 \mathrm{~cm} \mathrm{(} \pm$ $0.186), 20.940 \mathrm{~cm}( \pm 0.154), 13.447 \mathrm{~cm} \mathrm{(} \pm$ $0.132), 14.360 \mathrm{~cm}( \pm 0.201), 16.340 \mathrm{~cm} \mathrm{(} \pm$ $0.117)$ and $13.587 \mathrm{~cm}( \pm 0.124)$, respectively. Figure 2 is a bar chart illustrating the difference in the length values. The lengths of all these long bones were statistically different $(p<0.001)$, with the Yankasa sheep being longer.

Table I presented the diameters of the proximal extremities of the long bones in the two species. The difference in diameter of proximal extremity of the femur is not statistically significant ( $p>$ 
0.05). Conversely, the differences in the proximal extremity of other long bones were of statistical importance at varying degree of probabilities, with that of the Yankasa sheep being wider than the Red Sokoto goat.

The diameter of the mid-shafts of long bones in the two species is presented in Table II. The differences in the mid-shaft diameter of the humerus, metacarpal III, femur, tibia and metatarsal III between the Yankasa sheep and the Red Sokoto goat differs significant $(\mathrm{p}<$ 0.001), with the Yankasa sheep being wider than the Red Sokoto goat. Furthermore, the

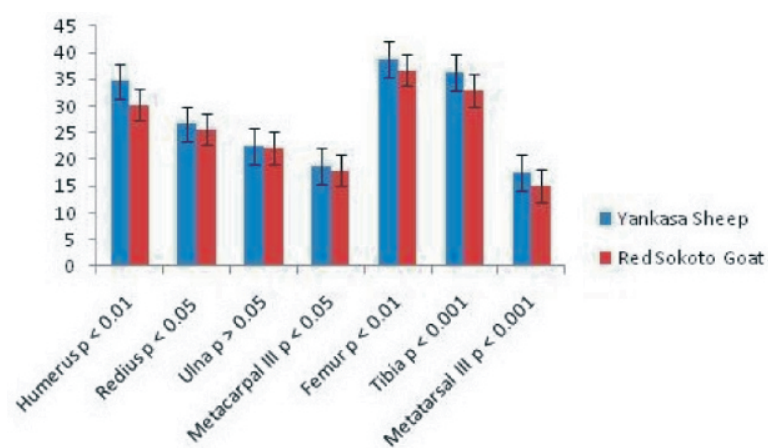

Figure 1: Bar chart illustrating the difference in the mean weights of the limb bones of Yankasa sheep and Red Sokoto goat differences in the mid-shaft diameters of the radius and ulna between the two species were statistically significant $(\mathrm{p}<0.05)$.

The diameters of the distal extremity of the humerus, ulna and femur did not vary significantly ( $p>0.05)$ as seen in Table III. However, the diameters of the distal extremities of the radius, metacarpal III, tibia and metatarsal III were of a very high statistical difference ( $\mathrm{p}<$ 0.001 ) between the two species with that of the Yankasa sheep being significantly wider than that of the Red Sokoto goat.

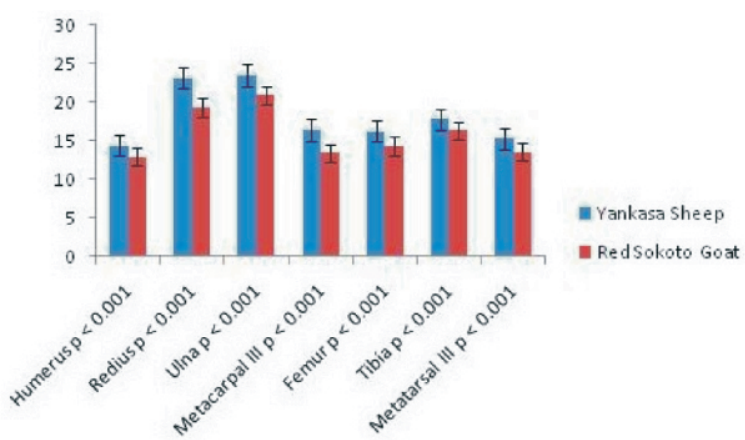

Figure 2: Bar chart illustrating the difference in the mean lengths of the limb bones of Yankasa sheep and Red Sokoto goat

Table I: Mean diameters of proximal long bones of Yankasa sheep and Red Sokoto goat limbs in centimetres $(\mathrm{cm})$

\begin{tabular}{|l|c|c|c|c|l|l|l|}
\hline \multicolumn{1}{|c|}{ Specie } & Humerus & Radius & Ulna & Metacarpal III & Femur & Tibia & Metatarsal III \\
\hline $\begin{array}{l}\text { Yankasa } \\
\text { Sheep }(n=15)\end{array}$ & $2.338 \pm 0.021$ & $2.283 \pm 0.042$ & $1.501 \pm 0.02$ & $2.006 \pm 0.030$ & $2.349 \pm 0.023$ & $2.149 \pm 0.016$ & $1.9923 \pm 0.023$ \\
$\begin{array}{l}\text { Red Sokoto } \\
\text { Goat }(n=15)\end{array}$ & $1.833 \pm 0.070^{* * *}$ & $2.176 \pm 0.031^{*}$ & $1.060 \pm 0.020^{* * *}$ & $1.737 \pm 0.020^{* * *}$ & $2.279 \pm 0.023 N S$ & $1.910 \pm 0.029^{* * *}$ & $1.880 \pm 0.021^{* *}$ \\
\hline
\end{tabular}

NS Non significant difference $(p>0.05) ;{ }^{*}$ Significant difference $(p<0.05) ;{ }^{* *}$ High significant difference $(p<0.01)$;

${ }^{* * *}$ Very high significant difference $(p<0.001)$

Table Il: Mean diameters of mid-shaft of long bones of Yankasa sheep and Red Sokoto goat limbs in centimetres (cm)

\begin{tabular}{|l|l|l|l|l|l|l|l|}
\hline Specie & Humerus & Radius & Ulna & Metacarpal III & Femur & Tibia & Metatarsal III \\
\hline $\begin{array}{l}\text { Yankasa } \\
\text { Sheep }(n=15)\end{array}$ & $1.579 \pm 0.03$ & $1.495 \pm 0.020$ & $1.136 \pm 0.046$ & $1.710 \pm 0.019$ & $1.662 \pm 0.025$ & $1.454 \pm 0.016$ & $1.456 \pm 0.011$ \\
$\begin{array}{l}\text { Red Sokoto } \\
\text { Goat }(n=15)\end{array}$ & $1.369 \pm 0.026^{* * *}$ & $1.447 \pm 0.017^{*}$ & $0.985 \pm 0.019^{*}$ & $1.485 \pm 0.014^{* * *}$ & $1.472 \pm 0.013^{* * *}$ & $1.324 \pm 0.017^{* \star *}$ & $1.329 \pm 0.015^{* * *}$ \\
\hline
\end{tabular}

${ }^{* * *}$ Very high significant difference $(p<0.001) ;{ }^{*}$ Significant difference $(p<0.05)$

Table III: Mean diameters of distal long bones of Yankasa sheep and Red Sokoto goat limbs in centimetres (cm)

\begin{tabular}{|l|l|l|l|l|l|l|l|}
\hline Specie & Humerus & Radius & Ulna & Metacarpal III & Femur & Tibia & Metatarsal III \\
\hline $\begin{array}{l}\text { Yankasa } \\
\text { Sheep }(n=15)\end{array}$ & $1.769 \pm 0.043$ & $1.784 \pm 0.023$ & $1.156 \pm 0.015$ & $1.942 \pm 0.028$ & $2.180 \pm 0.026$ & $2.042 \pm 0.022$ & $1.897 \pm 0.023$ \\
$\begin{array}{l}\text { Red Sokoto } \\
\text { Goat }(n=15)\end{array}$ & $1.741 \pm 0.075 \mathrm{NS}$ & $1.413 \pm 0.017^{* * *}$ & $1.109 \pm 0.018 \mathrm{NS}$ & $1.570 \pm 0.022^{* * *}$ & $2.108 \pm 0.013 \mathrm{NSS}$ & $1.815 \pm 0.035^{* * *}$ & $1.718 \pm 0.020^{* * *}$ \\
\hline
\end{tabular}

*** Very high significant difference; NS Non significant difference $(p>0.05)$ 


\section{DISCUSSION}

It is an established fact that bone growth in weight and length depends primarily on the amount of calcium salt deposited during ossification (Richardson et al., 1976). This in turn depends on the quantity of the mineral in animal feed, and the ability of the animal to use the mineral for bone calcification (Sivachelvan et al., 1996). It is therefore, pertinent to point out that the nutritional status of animals from which the bone specimens were collected were unknown. The results of this study however, showed that long bones of Yankasa sheep are generally heavier, longer and greater than those of Red Sokoto goats in all the parameters measured. The differences in length of all the bones measured were statistically significant ( $\mathrm{p}$ $<0.001$ ). This finding can be related to specie differences in that the state of growth and development of bone in different species varied over a wide limit (Harris, 1937). This range of bone development is from extreme pre-maturity, as in rat and humans to extreme post-maturity as found in ruminants (Bryden et al., 1972).

Several factors have been reported to influence the growth and development of bone tissue. Vaughan, (1980) classified these factors into two main groups: Endogenous (genetic and hormonal) and Exogenous (environmental and dietary) factors. These two broad factors also interact with each other to affect bone development and growth (Lawrence and Fowler, 1997). Of these factors, the endogenous factor is of more relevance to this study since as stated earlier, the nutritional status of the animals used was not considered. In this case the differences in the measurements taken from the long bones of the two species are based on genetic and intrinsic growth factors inherent in the two species.

This study showed that long bones of Yankasa sheep were significantly longer than that of Red Sokoto goats. Also, the mid shaft diameters of these bones in the Yankasa sheep are significantly wider than that of the Red Sokoto goats. This high osteometric value of long bones in Yankasa sheep relative to Red Sokoto goat is a genetic factor due to specie disposition. Thus, it is expected to be constant for healthy ruminants of these two species.
In conclusion, this study has provided a means of differentiating long bones from the remains of Yankasa sheep and Red Sokoto goats in zooarchaeological studies and during gross anatomy practical session.

\section{References}

AFOLAYAN, R. A., ADEYINKA, I. A. and LAKPINI, C. A. M. (2006): The estimation of live weight from body measurements in Yankasa sheep. Czech J. Anim. Sci. 51: 343-348.

BRYDEN, M. M., EVANS, H. E. and BINNS, W. (1972): Embryology of sheep 1. Extraembryonic membranes and the development of body form. J. Morphol. 8: 169-186.

CORBET, G. B. (1978): The mammals of the Palaearctic Region. A taxonomic Review. British Museum (Natural History): London, UK.

CORBET, G. B. and HILL, J. E. (1980): A World List of Mammalian Species. British Museum (Natural History): London, UK.

EPSTEIN, H. (1971): The Origin of the Domestic Animals of Africa. Africana Publishing Corporation: New York, USA.

GUINTARD, C. and LALLEMAND, M. (2003): Osteometric study of metapodial bones in sheep (Ovis aries, L. 1758). Ann. Anat. 185: 573-583.

HARRIS, H. A. (1937): The foetal growth of the sheep. J. Anat. 71: 517-527.

LAWRENCE, T. L. J. and FOWLER, V. R. (1997): Supportive connective tissue. In: Bone and cartilages. CAB Internet Wallingford Oxon UK, 3649.

RICHARDSON, C., HERBERT, C. N. and TERILEKI, S. (1976): Estimation of the developmental age of the ovine foetus and lamb. Vet. Rec. 99: 22-26.

RYDER, M. L. (1984): Sheep. In: Evolution of Domesticated Animals. Mason, I. L. (Ed) Longmans: London, UK.

SALAKO, A. E. (2006a): Principal component factor analysis of the morphostructure of immature Uda sheep. Int. J. Morphol. 24: 571-774.

SALAKO, A. E. (2006b): Application of Morphological Indices in the Assessment of Type and Function in Sheep. Int. J. Morphol. 24: 13-18.

SIVACHELVAN, M. N., GHALI, M. and CHIBUZO, G. A. (1996): Foetal age estimation in sheep and goats. Small Ruminant Res. 19: 69-76.

VAUGHAN, J. M. (1980): The physiology of bone. Oxford University press London. New York, 158165.

WATSON, J. P. N. (1972): Fragmentation analysis of animal bone samples from archaeological sites. Archaeometry, 14: 221-228.

WILSON, R. T. (1991): Small Ruminant Production and the Small Ruminant Genetic Resource in Tropical Africa. Food and Agriculture organization of the United Nations, Rome.

Zeuner, F. E. (1963): A History of Domesticated Animals. Hutchinson: London, UK. 